\title{
TWO UNRELATED CASES OF SINGLE MAXILLARY CENTRAL INCISOR WITH 7q TERMINAL DELETION
}

\author{
Mitsuo Masuno, ${ }^{1, *}$ Yoshimitsu Funushima, ${ }^{1}$ Yoshitsugu Sugio, ${ }^{1}$ \\ Masakazu IKeDA ${ }^{2}$, and Yoshikazu KURoKI ${ }^{1}$ \\ ${ }^{1}$ Division of Medical Genetics and ${ }^{2}$ Department of Dentistry, Kanagawa Children's \\ Medical Center, Minami-ku, Yokohama 232, Japan
}

\begin{abstract}
Summary Two unrelated cases of single maxillary central incisor (SMCI) with $7 \mathrm{q}$ terminal deletion of the same breakpoint at $7 \mathrm{q} 36.1$ were described. They had mental retardation, microcephaly, hypotelorism, short stature, and normal levels of plasma growth hormone. One case had bilateral caudal ectopic kidneys, double renal pelves, and dilated ureters. The other had bilateral hydroureteronephrosis. The present cases suggest that $7 \mathrm{q}$ terminal deletion is one of the causes of SMCI.

Key Words single maxillary central incisor, $7 \mathrm{q}$ terminal deletion, urological abnormalities
\end{abstract}

\section{INTRODUCTION}

Single maxillary central incisor (SMCI) is noted in both deciduous and permanent dentition, usually associated with midfacial hypoplasia and normal intelligence. Rappaport et al. (1977) reported seven patients with short stature and SMCI. Five of the patients had growth hormone insufficiencies. In contrast, some cases in SMCI with normal height were reported (Bartholomew et al., 1987; Berry et al., 1984; Fryns and Van den Berghe, 1988; Hattori et al., 1987; Lowry, 1974; Maréchaux, 1986; Santoro and Wesley, 1983; Scott, 1958; Wesley et al., 1978; Winter et al., 1982). So far chromosomal abnormality associated with SMCI is only two unrelated cases with 18p - (Boudailliez et al., 1983; Dolan et al., 1981). Two unrelated cases of SMCI with 7q terminal deletion of the same breakpoint at $7 \mathrm{q} 36.1$ were here reported.

Received October 1, 1990; revised version received October 29, 1990; Accepted November 7, 1990.

* Present address: Department of Pediatrics, Gifu University School of Medicine, 40 Tsukasa, Gifu 500 , Japan. 


\section{CASE REPORTS}

Case 1. The patient, KCMC 101702, 2 6/12-year-old female was the first product of a 27 -year-old mother and a 27 -year-old father, who were non-consanguineous. She was born at 38 weeks of gestation. Birth weight was 2,754 g. APGAR scores were 3 at 1 min. Tube-feeding was required for 6 months on account of poor sucking. She has suffered from febrile convulsions from 10 months of age. She was first examined by us at 2 years 6 months of age because she was severely retarded. Her body weight was $8.9 \mathrm{~kg}$ ( -2.3 S.D.), height $80.5 \mathrm{~cm}(-2.3$ S.D.), head circumference $42.2 \mathrm{~cm}(-3.7$ S.D.). DQ was 46. Main clinical features included midfacial hypoplasia, hypotelorism, depressed nasal tip, hypoplastic

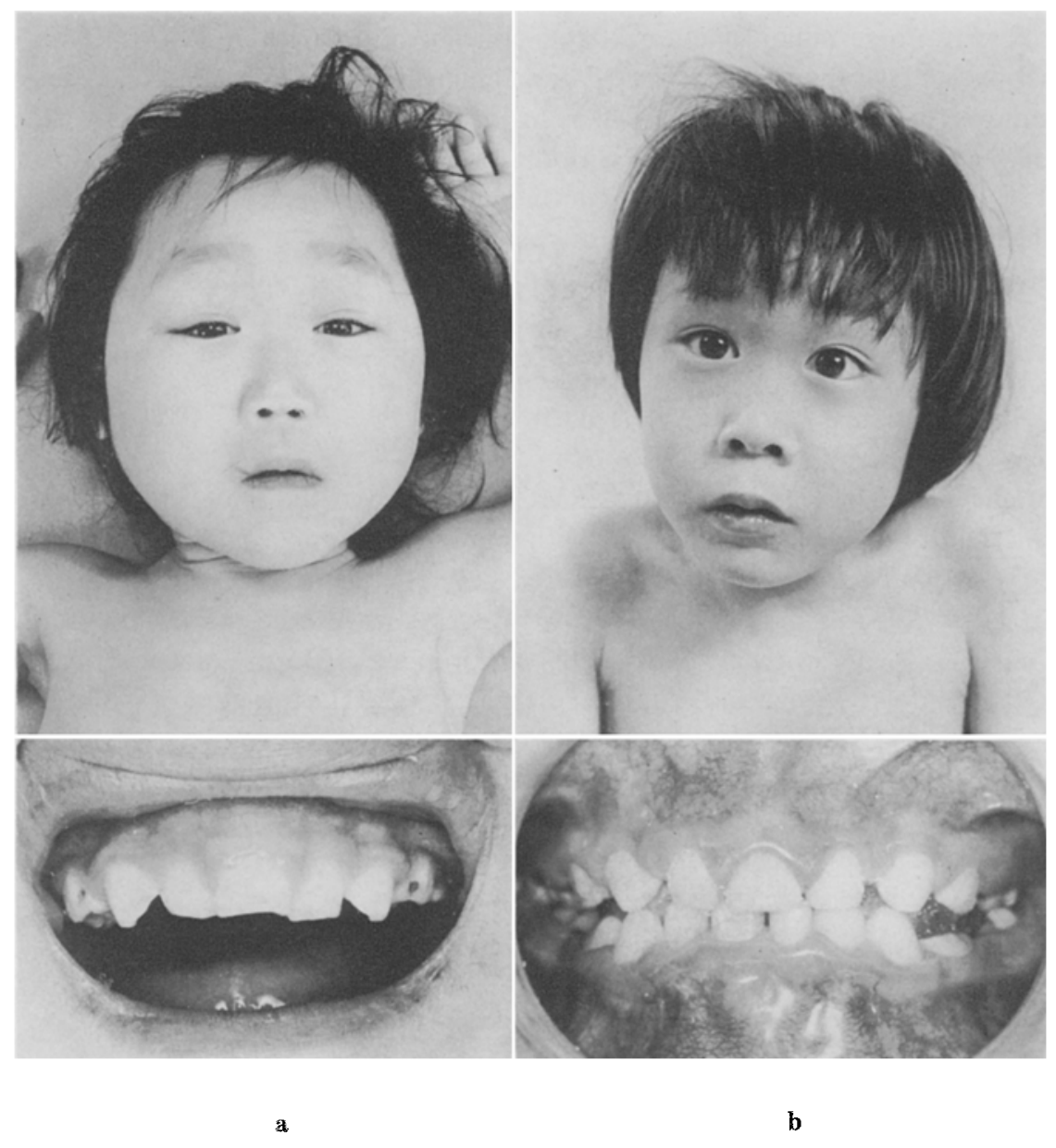

Fig. 1. Front view and single maxillary central incisor of case 1(a) and of case 2(b). 
Table 1. Dermatoglyphic findings of the proband.

TFRC: 151

\begin{tabular}{|c|c|c|c|c|c|c|c|c|c|c|}
\hline & & & & & 2 & & 3 & & & 5 \\
\hline Left hand & & & $\mathrm{J}$ & & W & & $\mathrm{W}$ & & & $\mathrm{U}$ \\
\hline Right hand & & & & & $\mathrm{W}$ & & w & & & W \\
\hline \multicolumn{11}{|c|}{ Palmar formula } \\
\hline Left: & 11. & 7. & 7. & 3. & $13^{\prime}$ & $-\mathrm{t}^{\prime}-$ & 0. & $0 . / 0$. & 0. & $\mathrm{~L}$. \\
\hline Right: & 11. & 7. & 7. & 3. & $13^{\prime}$ & $-t-$ & 0. & 0. / 0. & 0. & L. \\
\hline
\end{tabular}

$\mathrm{U}$, ulnar loop; W, whorl.

columella, left narrow nasal cavity, high-arched palate, single maxillary central incisor, and clinodactyly of the left 5th finger (Fig. 1a). Computerized tomography of the head, EEG, and ocular fundi were normal. Systemic bone survey showed "J-shaped" sella and absence of the lower portion of sacrum. Bone age was retarded (1 year 5 months). Intravenous pyelography showed bilateral caudal ectopic kidneys, double renal pelves, and dilated ureters. She had no history of urinary tract infection. Dermatoglyphics was shown in Table 1.

Case 2. The patient, KCMC 46975, 7 2/12-year-old male, was the first product of a 26-year-old mother and a 27-year-old father, who were unrelated. He was born at 38 weeks of gestation. Birth weight was $2,128 \mathrm{~g}$. He was afflicted with pyelonephritis at 6 years of age. He was first examined by us at 7 years 2 months of age because of severe mental retardation. His body weight was $13.0 \mathrm{~kg}(-2.6$ S.D.), height $95.5 \mathrm{~cm}$ ( -5.0 S.D.), head circumference $44.5 \mathrm{~cm}$ (-5.1 S.D.). DQ was 23. Main clinical features were midfacial hypoplasia, esotropia, hypotelorism, hypoplastic columella, single maxillary central incisor, scoliosis, and hearing loss due to secretory otitis media (Fig. 1b). Computerized tomography of the head, $\mathrm{EEG}$, and fundi were normal. Bone survey showed fusion at the vertebral margin between right 11 th and 12 th costa and spina bifida occulta of sacrum. Bone age was retarded ( 4 years 4 months). Intravenous pyelography showed bilateral hydroureteronephrosis. Dermatoglyphics was abnormal: right hypothenar pattern and left distal axial triradius $\left(\mathrm{t}^{\prime \prime}\right)$.

\section{LABORATORY DATA}

Case 1. Examinations of the blood, serum and urine revealed normal. Growth hormone (GH), thyroid stimulating hormone (TSH), luteinizing hormone (LH), follicle stimulating hormone (FSH), and prolactin (PRL) levels were all within normal range.

Case 2. Examinations of the blood, serum and urine revealed normal. GH, TSH, LH, FSH, and PRL levels were normal. 


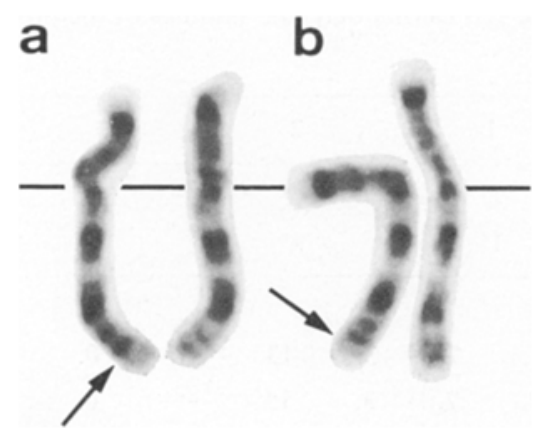

Fig. 2. Partial karyotype with high resolution $G$ banding of case 1(a) and case 2(b). Arrows show the breakpoint of $7 \mathrm{q} 36.1$.

\section{CYTOGENETIC FINDINGS}

Case $\ell$. The karyotype of the proband by GTG high resolution technique was 46,XX,del(7)(pter $\rightarrow q 36.1$ ) (Fig. 2a). The parents showed normal karyotype.

Case 2. The karyotype of the proband revealed $46, X Y$, del $(7)(\operatorname{pter} \rightarrow q 36.1:)$ with the same breakpoint as Case 1 (Fig. 2b). The chromosome analysis of the parents were not permitted.

\section{DISCUSSION}

Thirty-five cases of SMCI including our five were reviewed (Bartholomew et al., 1987; Bazan, 1983; Berry et al., 1984; Boudailliez et al., 1983; Dolan et al., 1981; Ellisdon and Marshall, 1970; Fryns and Van den Berghe, 1988; Hattori et al., 1987; Hayward, 1979; Liberfarb et al., 1987; Lowry, 1974; Maréchaux, 1986; Mofson and Seidberg, 1974; Parker and Vann, 1985; Poyton et al., 1969; Rappaport et al., 1977; Santoro and Wesley, 1983; Scott, 1958; Vanelli et al., 1980; Wesley et al., 1978; Winter et al., 1982). Fourteen cases were males and 21 were females. Short stature was present in 16 cases out of 31 cases. GH insufficiency was observed in 7 out of 16 . Hypotelorism was noticed in 15 out of 19 . Mental retardation was present in 5/24. Microcephaly, 7/20. Chromosome abnormality was observed in $4 / 16$. Two unrelated cases of SMCl with $18 \mathrm{p}-$ were reported (Boudailliez et al., 1983; Dolan et al., 1981). They had short stature, mental retardation, and microcephaly but there was no description about urological abnormalities. The present two cases with SMCI had the same karyotype of del(7)(pter $\rightarrow \mathrm{q} 36.1)$. Thus, $7 q-$ is suggested to be another closely related chromosome anomaly to SMCI with mental retardation, microcephaly, and urological abnormalities. In addition, we examined other three cases of SMCI with normal intelligence and normal head circumference. Chromosome analysis of all three revealed normal. Thus, chro- 
mosome analysis is recommended for the SMCI cases with mental retardation and microcephaly. Intravenous pyelography is also recommended to detect urological anomalies in SMCI with $7 q-$.

In each four families with affected offspring with holoprosencephaly, one of parents was found to have SMCI and hypotelorism (Berry et al., 1984; Fryns and Van den Berghe, 1988; Hattori et al., 1987; Lowry, 1974). In another report a woman suffered from hyposmia had a child with SMCI and ocular coloboma (Liberfarb et al., 1987). These families may represent that SMCI is a less severe form of holoprosencephaly transmitted as an autosomal dominant fashion. A hereditary "missing" maxillary central incisor was noticed in a mother and her daughter (Kopp, 1967): however, we consider that it is not "missing" but SMCI judging by the photographs. Thus, the etiology of SMCI seems to be heterogeneous.

$7 \mathrm{q}$ terminal deletion syndrome is characterized by developmental delay, pre- and postnatal growth retardation, generalized hypotonia, abnormal EEG with or without seizures, feeding problems in infancy, microcephaly, prominent forehead, ocular hypertelorism, eye defects, broad nasal bridge, bulbous nasal tip, auricular malformations, micrognathia, chest abnormalities, genital malformations in males, and abnormal palmar and plantar creases. The patients with less deleted material from $7 \mathrm{q} 35 \rightarrow$ qter resemble quite closely to the phenotype of the patients with monosomy of $7 \mathrm{q} 32 \rightarrow$ qter (Kodama et al., 1980; Young et al., 1984). The clinical features, especially facial appearance including SMCI, of our two patients apparently differ from those of the patients with a terminal deletion of $7 \mathrm{q}$ distal to $\mathrm{q} 35$ (Francke, 1978; Lambert et al., 1981; Turleau et al., 1979; Young et al., 1984). It might imply that $7 \mathrm{q} 35$ is the critical segment compatible with typical terminal $7 \mathrm{q}-$ syndrome, and that at least one of the genes influencing the occurrence of SMCI is located on $7 q 36.1 \rightarrow$ qter. Both of the present cases had urinary tract malformations. Urological abnormalities including double ureters, double pelves, hydronephrosis, hydroureters, stenosis of the diaphragmatic part of the urethra, horseshoe kidneys, vesicoureteral reflux, and renal cystic dysplasia are rarely found in the patients with distal 7q deletions (Kajii and Murano, 1984; Schinzel, 1984, 1986; Shokeir, 1973). Two cases of holoprosencephaly and hydronephrosis with $\operatorname{del}(7 \mathrm{q})$ (Lurie et al., 1990) and our two cases of SMCI and urological abnormalities with 7q terminal deletion suggest the association between holoprosencephaly and SMCI. It is important to reinvestigate whether SMCI is present in the previously reported cases with $7 q$ terminal deletion.

\section{REFERENCES}

Bartholomew, D.W., Jabs, E.W., Levin, L.S. and Ribovich, R. 1987. Single maxillary central incisor and coloboma in hypomelanosis of Ito. Clin. Genet. 32: 370-373.

Bazan, M.T. 1983. Fusion of maxillary incisors across the midline: clinical report. Pediatr. Dent. 5: 220-221.

Berry, S.A., Pierpont, M.E. and Gorlin, R.J. 1984. Single central incisor in familial holopro- 
sencephaly. J. Pediatr. 104: 877-880.

Boudailliez, B., Morichon-Delvallez, N., Goldfarb, A., Pautard, J.C., Lenaerts, C. and Piussan, C. 1983. Incisive supérieure unique, hypopituitarisme et anomalie chromosomique monosomie 18p. J. Génét. Hum. 31: 239-242.

Dolan, L.M., Willson, K. and Wilson, W.G. 1981. 18p- syndrome with a single central maxillary incisor. J. Med. Genet. 18: 396-398.

Ellisdon, P.S. and Marshall, K.F. 1970. Connation of maxillary incisors. Br. Dent. J. 129:16-21.

Francke, U. 1978. Hageman (Factor XII) locus on $7 \mathrm{q}$ ?: report of a second case with del(7)q35 and normal factor XII level. Hum. Genet. 45: 363-367.

Fryns, J.P. and Van den Berghe, H. 1988. Single central maxillary incisor and holoprosencephaly. Am. J. Med. Genet. 30: 943-944.

Hattori, H., Okuno, T., Momoi, T., Kataoka, K., Mikawa, H. and Shiota, K. 1987. Single central maxillary incisor and holoprosencephaly. Am. J. Med. Genet. 28: 483-487.

Hayward, J.R. 1979. Observations on midline deformity and the solitary maxillary central incisor syndrome. J. Hosp. Dent. Pract. 13: 113-114.

Kajii, T. and Murano, I. 1984. A 7q - son of an XYY father. Jpn. J. Human Genet. 29: 387-389.

Kodama, Y., Narahara, K., Yabuuchi, H., Hirano, A., Inoue, H., Kimura, S. and Kimoto, H. 1980. A case with a terminal deletion of the long arm of chromosome 7. Jpn. J. Human Genet. 25: 329-335.

Kopp, W.K. 1967. A hereditary congenitally missing maxillary central incisor. Oral. Surg. 24: 367.

Lambert, J.C., Mariani, R., Donzeau, M., Ferrari, M., Boutte, P. and Ayraud, N. 1981. La monosomie 7qter: a propos d'une observation. Arch. Fr. Pediatr. 38: 177-180.

Liberfarb, R.M., Abdo, O.P. and Pruett, R.C. 1987. Ocular coloboma associated with a solitary maxillary central incisor and growth failure: manifestations of holoprosencephaly. Ann. Ophthalmol. 19: 226-227.

Lowry, R.B. 1974. Holoprosencephaly. Am. J. Dis. Child. 128: 887.

Lurie, I.W., Ilyina, H.G., Podleschuk, L.V., Gorelik, L.B. and Zaletajev, D.V. 1990. Chromosome 7 abnormalities in parents of children with holoprosencephaly and hydronephrosis. $\mathrm{Am}$. J. Med. Genet. 35: 286-288.

Maréchaux, S.C. 1986. The single maxillary central primary incisor: report of case. J. Dent. Child. 53: 124-126.

Mofson, E.R. and Seidberg, B.H. 1974. Congenital single incisor. Oral Surg. 38: 490.

Parker, P.R. and Vann, W.F., Jr. 1985. Solitary maxillary central incisor: clinical report. Pediatr. Dent. 7: 134-136.

Poyton, H.G., Morgan, G.A. and Levine, N. 1969. Median incisor fusion. Oral. Surg. 28: 7678.

Rappaport, E.B., Ulstrom, R.A., Gorlin, R.J., Lucky, A.W., Colle, E. and Miser, J. 1977. Solitary maxillary central incisor and short stature. J. Pediatr. 91: 924-928.

Santoro, F.P. and Wesley, R.K. 1983. Clinical evaluation of two patients with a single maxillary central incisor. J. Dent. Child. 50: 379-381.

Schinzel, A. 1984. Cyclopia and cebocephaly in two newborn infants with unbalanced segregation of a familial translocation $\mathrm{rcp}(1 ; 7)(\mathrm{q} 32 ; \mathrm{q} 34)$. Am. J. Med. Genet. 18: 153-161.

Schinzel, A. 1986. A further case of cyclopia due to unbalanced segregation of a previously reported $\operatorname{rcp}(1 ; 7)(\mathrm{q} 32 ; \mathrm{q} 34)$ familial translocation. Am. J. Med. Genet. 24: 205-206.

Scott, D.C. 1958. Absence of upper central incisor. Br. Dent. J. 104: 247-248.

Shokeir, M.H.K. 1973. Deletion of the long arm of chromosome no. 7 : tentative assignment of the Kidd (JK) locus. Clin. Genet. 4: 360-368.

Turleau, C., de Grouchy, J,, Perignon, F. and Lenoir, G. 1979. Monosomie 7qter. Ann. Génét. 22: 242-244. 
Vanelli, M., Bernasconi, S. and Balestrazzi, P. 1980. Incisive supérieure unique et déficit en STH. Arch. Fr. Pediatr, 37: 321-322.

Wesley, R.K., Hoffman, W.H., Perrin, J. and Delaney, J.R. 1978. Solitary maxillary central incisor and normal stature. Oral. Surg. 46: 837-842.

Winter, W.E., Rosenbloom, A.L., Maclaren, N.K. and Mickle, J.P. 1982. Solitary central maxillary incisor associated with precocious puberty and hypothalamic hamartoma. J. Pediatr. 101: 965-967.

Young, R.S., Weaver, D.D., Kukolich, M.K. Heerema, N.A., Palmer, C.G., Kawira, E.L. and Bender, H.A. 1984. Terminal and interstitial deletions of the long arm of chromosome $7:$ a review with five new cases. Am. J. Med. Genet. 17:437-450. 